\title{
Implementation of the Beta Distribution Parameter Estimation Method on Empirical Bayes of Small Area Estimation
}

\author{
Siti Rafika Fiandasari ${ }^{1}$, Margaretha Ari Anggorowati ${ }^{2}$ \\ \{siti.rafika@bps.go.id ${ }^{1}$, m.ari@bps.go.id $\left.{ }^{2}\right\}$ \\ Badan Pusat Statistik Sumbawa Barat, Pendidikan Street Telaga Bertong Taliwang Sumbawa Barat ${ }^{1}$, \\ Badan Pusat Statistik Jakarta Indonesia, Dr. Sutomo Street 6-8 Jakarta Indonesia ${ }^{2}$
}

\begin{abstract}
There is a problem when the amount of available sample is not sufficient for estimating a parameter in sampel survey. Small Area Estimation can handle the problem with use additional variable, but there is a problem when the additional variable hard to get or not strong enough to correlate with the response variable. Empirical Bayes method can handle that because it does not need an additional variable, but there are $\alpha$ and $\beta$ in that method which needs to be estimated. This research uses four methods for estimating $\alpha$ and $\beta$ that is Moment and Newton Raphson by Rao, Moment and Newton Raphson by Claire. Moment by Claire, Moment and Newton Raphson by Rao are more effective than Newton Raphson by Claire while Empirical Bayes estimator are more effective than direct estimator.
\end{abstract}

Keywords: Claire, Empirical Bayes, Rao, Small Area Estimation.

\section{Introduction}

A sample survey is one of the methods of collecting data by taking part in the population unit. The result of the survey that obtained before will produce data that further, the data become a piece of information by certain statistical method. The information is used by decision makings like a government agency or non-government agancy to deciding the more proper policy. The form of policy like eradicating poverty, equitable income distribution, government fund allocation, or other business decision.

There are several agencies that need data on smaller areas like sub-district or village for a make on a more efficient policy at this time. However, most of the surveys conducted by certain statistical agency especially in Indonesia conducted in the national, provincial, and regency levels. This is because of several problems in the cost, energy, and time needed in the survey. If the available data forced to estimate the characteristics of a smaller area population then it will produce greater error variance because of the insufficient number of the sample (Rao \& Molina, 2015).

Small Area Estimation (SAE) can be used to resolving the problem in estimating a smaller area population by using additional variables. These additional variables are assumed not to contain an error so it can be obtained from administrative data, village potential, and census (Rao, 2003). However, there is a problem when the additional variable is hard to find, not strong enough to correlate with the response variable or containing a certain error. There 
are two levels in SAE that is area level and unit level (Rao, 2003). Area level on SAE uses the data obtained from the result of population estimation in the area while the unit level in SAE uses the data that is not containing an error or not the result of estimating population like the data of each household. One of the SAE methods is Empirical Best Linear Unbiased Prediction (EBLUP) which is a normal assumption needed for getting an accurate MSE estimator and the type of data is continuous (Rao \& Molina, 2015). It becomes difficult when the type of data is binary and normal assumption is hard to fulfill so it needs to do the transformation. The result from transformation usually bias or mean of sampling error is not 0 when the number of samples is quite small so one of the ways to fix that is can use alternative ways with another method (Rao \& Molina, 2015). There is one of the SAE methods with unit-level that is Empirical Bayes (EB) Beta-Binomial with no covariate which does not require auxiliary variable and the type of data is binary so this method is used when the type of data is binary and the proper auxiliary variable is difficult to get (Rao, 2003).

From several types of research that have done before give the estimation result of SAE methods always more efficient than direct estimators. This is because of Mean Square Error (MSE) estimator of SAE always smaller than the MSE estimator of the sample survey. As well as EB Beta-Binomial with no covariate method gives the MSE and RRMSE estimator always smaller than MSE and RRMSE estimator of sample survey. Furthermore, most of the previous researches use moment Kleinman method for estimate $\alpha$ and $\beta$ values that are used in calculating the EB estimator and its MSE value. A few kinds of literature show that there is another method for estimate $\alpha$ and $\beta$ values like maximum likelihood. However, this method will give no closed form result so it needs to do with another iteration method like Newton Raphson (Rao \& Molina, 2015). But, this method is rarely used in several types of research so this research wants to carry out this method in the EB estimator. Eventually, this paper will carry out four methods for estimate $\alpha$ and $\beta$ values that are Moment and Newton Raphson by the book of J.N.K.Rao then Moment and Newton Raphson by a module of Claire Elayne Bangerter Owen. These four methods will be used for calculating EB estimator and its MSE value so the aim of this research is to see the implementation result of those four methods in EB Beta-Binomial with no covariate with a different characteristic of the data and to see comparison result between the direct estimator and EB estimator with their RRMSE value.

\section{Methods and Materials}

\subsection{Materials}

Source of the data used in this research is secondary data obtained from journals and BPS publications. The data used for this research come from 3 journals that is the graduating cumulative grade point average of randomly selected graduates of the University of Lagos from a journal titled "Bayesian Estimation of Above-Average Performance in Tertiary Institutions: A Case Study of University of Lagos, Akoka, Nigeria." which is the data has more proportion of "success" data. The second data used in this research is the proportion of students who used the motorcycle in each faculty from a journal titled "A Bayesian Model for Estimation of Population Proportions" which is the data has a moderate proportion of 
"success" data. And the third data used in this research is the proportion of health card ownership status in Yogyakarta from a journal titled "Penerapan Metode Bayes Empirik pada Penggunaan Area Kecil untuk Kasus Biner." which is the data has a fewer proportion of "success" data. Furthermore, this study use data from the BPS publication titled "Data dan Informasi Kemiskinan Kabupaten/Kota Tahun 2017." and use generated data from normal distribution to see the performance of each method in each characteristics of the data.

\subsection{Methods}

To get a value of direct estimator and its MSE value, canbe obtained by the result of calculating "success" proportion and its variance value in each area with

$$
\begin{aligned}
& \hat{p}_{i}=\frac{y_{i}}{n_{i}} ; i=1,2, \ldots, m . \\
& \operatorname{Var}\left(\hat{p}_{i}\right)=\frac{\hat{p}_{i}\left(1-\hat{p}_{i}\right)}{n_{i}} .
\end{aligned}
$$

where $\hat{p}_{i}=$ "success" proportion in $i^{\text {th }}$ area, $y_{i}=$ the amount of "success" sample unit in $i^{t h}$ area, $n_{i}=$ the amount of sample in $i^{t h}$ area, and $m=$ the amount of area(Zain \& Sidabutar, 2015).To get the value of the EB estimator will be obtained by calculating the parameter of $\alpha$ and $\beta$ first. There are 4 methods to calculate $\alpha$ and $\beta$ estimators in this research that are Moment method by Rao, moment by Claire, Newton Raphson by Rao, and Newton Raphson by Claire.

Moment by Rao.This method calculating $\alpha$ and $\beta$ estimators with

$$
\begin{aligned}
& \hat{\alpha}=\hat{p}\left[\frac{\hat{p}(1-\hat{p})\left[n_{T}-\sum_{i=1}^{m} \frac{n_{i}^{2}}{n_{T}}-(m-1)\right]}{n_{T} s_{p}^{2}-\hat{p}(1-\hat{p})(m-1)}-1\right] . \\
& \hat{\beta}=\hat{p}\left[\frac{\hat{p}(1-\hat{p})\left[n_{T}-\sum_{i=1}^{m} \frac{n_{i}^{2}}{n_{T}}-(m-1)\right]}{n_{T} s_{p}^{2}-\hat{p}(1-\hat{p})(m-1)}-1\right]\left[\frac{1}{\hat{p}}-1\right] .
\end{aligned}
$$

where $\hat{p}=\sum_{i=1}^{m}\left(n_{i} / n_{T}\right) \hat{p}_{i}, s_{p}^{2}=\sum_{i=1}^{m}\left(n_{i} / n_{T}\right)\left(\hat{p}_{i}-\hat{p}\right)^{2}, n_{T}=\sum_{i=1}^{m} n_{i}($ Rao $\quad \& \quad$ Molina, 2015).

Newton Raphson by Rao. In this method, we have to determining $\alpha$ and $\beta$ estimators obtained from the moment method as initial values (Wilcox, 1979). Also determining the amount of iteration maximum value as 100 and precision value as 0.0001 (Molina \& Marhuenda, 2015).In accordance with Rand R. Wilcox (1979), log-likelihood function on beta-binomial distribution is

$$
l(\mu, \tau)=c-\sum_{i=1}^{m}\left[\begin{array}{c}
\sum_{h=0}^{y_{i}-1} \log (\mu+h \tau)+ \\
\sum_{h=0}^{n_{i}-y_{i}-1} \log (1-\mu+h \tau)- \\
\sum_{h=0}^{n_{i}-1} \log (1+h \tau)
\end{array}\right]
$$


with $\mu=\frac{\alpha}{\alpha+\beta} ; \tau=\frac{1}{\alpha+\beta}$. Then do differentiation to $\log$-likelihood function so it yields vector $g$ as

$$
g=\left(\frac{\partial \ln l}{\partial \alpha}, \frac{\partial \ln l}{\partial \beta}\right) .
$$

Furthermore we have to do differentiation twice so it yields matrix $\Lambda 2 \times 2$ as

$$
\Lambda=\left(\begin{array}{ll}
\frac{\partial^{2} \ln l}{\partial^{2} \alpha} & \frac{\partial^{2} \ln l}{\partial \alpha \partial \beta} \\
\frac{\partial^{2} \ln l}{\partial \beta \partial \alpha} & \frac{\partial^{2} \ln l}{\partial^{2} \beta}
\end{array}\right) .
$$

To get $\alpha$ and $\beta$ estimators with the Newton Raphson method, can be obtained by

$$
(\hat{\alpha}, \hat{\beta})_{i}=\left(\hat{\alpha}_{M K}, \hat{\beta}_{M K}\right)-G \Lambda^{-1} \text {. }
$$

with $\hat{\alpha}_{M K}$ and $\hat{\beta}_{M K}$ are $\alpha$ and $\beta$ estimators that are obtained from Moment method.The iteration will stop when the iteration number exceeds 100 or $\max \left[\left(\frac{\widehat{\alpha}_{i+1}-\widehat{\alpha}_{i}}{\widehat{\alpha}_{i}}\right),\left(\frac{\widehat{\beta}_{i+1}-\widehat{\beta}_{i}}{\widehat{\beta}_{i}}\right)\right]$ is less than the precision value.

Moment by Claire. This method get $\alpha$ and $\beta$ values by

$$
\begin{aligned}
& \hat{\alpha}=\bar{y}\left(\frac{\bar{y}(1-\bar{y})}{s^{2}}-1\right) . \\
& \hat{\beta}=(1-\bar{y})\left(\frac{\bar{y}(1-\bar{y})}{s^{2}}-1\right) .
\end{aligned}
$$

where $\bar{y}=\frac{\sum_{i=1}^{m} y_{i}}{m}$ and $S^{2}=\frac{1}{m-1} \sum_{i=1}^{m}\left(y_{i}-\bar{y}\right)^{2}$ (Owen, 2008).

Newton Raphson by Claire. First of all, we have to determining $\alpha$ and $\beta$ estimators obtained from the moment method as initial values (Wilcox, 1979). Also determining the amount of iteration maximum value as 100 and precision value as 0.0001 (Molina \& Marhuenda, 2015). To calculating vector $g=\left[g_{1}, g_{2}\right]$, can be obtainedby calculating

$$
\begin{aligned}
& g_{1}=\psi(\alpha)-\psi(\alpha+\beta)-\frac{1}{m} \sum_{i=1}^{m} \log \left(y_{i}\right) . \\
& g_{2}=\psi(\beta)-\psi(\alpha+\beta)-\frac{1}{m} \sum_{i=1}^{m} \log \left(1-y_{i}\right) .
\end{aligned}
$$

with $\psi(\alpha)=\frac{\Gamma^{\prime}(\alpha)}{\Gamma(\alpha)} ; \psi(\beta)=\frac{\Gamma^{\prime}(\beta)}{\Gamma(\beta)} ; \psi(\alpha+\beta)=\frac{\Gamma^{\prime}(\alpha+\beta)}{\Gamma(\alpha+\beta)}$. Next step is calculating matrix $\boldsymbol{G}$ as

$$
\boldsymbol{G}=\left(\begin{array}{ll}
\frac{d g_{1}}{d \alpha} & \frac{d g_{1}}{d \beta} \\
\frac{d g_{2}}{d \alpha} & \frac{d g_{2}}{d \beta}
\end{array}\right) .
$$


with $\frac{d g_{1}}{d \alpha}=\psi^{\prime}(\alpha)-\psi^{\prime}(\alpha+\beta) ; \frac{d g_{1}}{d \beta}=\frac{d g_{2}}{d \alpha}=-\psi^{\prime}(\alpha+\beta) ; \frac{d g_{2}}{d \beta}=\psi^{\prime}(\beta)-\psi^{\prime}(\alpha+\beta)$ where $\psi^{\prime}(x)=\frac{\Gamma^{\prime \prime}(x)}{\Gamma(x)}-\frac{\Gamma^{\prime}(x)^{2}}{\Gamma(x)^{2}}, x=\alpha, \beta, \alpha+\beta$. Finally, $\alpha$ and $\beta$ estimators are obtained with this method by

$$
(\hat{\alpha}, \hat{\beta})_{i+1}=(\hat{\alpha}, \hat{\beta})_{i}-\boldsymbol{G}^{-1} g
$$

The iteration will stop when the iteration number exceeds 100 or $\max \left[\left(\frac{\widehat{\alpha}_{i+1}-\widehat{\alpha}_{i}}{\widehat{\alpha}_{i}}\right),\left(\frac{\widehat{\beta}_{i+1}-\widehat{\beta}_{i}}{\widehat{\beta}_{i}}\right)\right]$ is less than the precision value.

To get EB estimator value will be obtained by calculate

$$
\hat{p}_{i}^{E B}=\hat{p}_{i}^{B}(\hat{\alpha}, \hat{\beta})=\hat{\gamma}_{i} \hat{p}_{i}+\left(1-\hat{\gamma}_{i}\right) \hat{p}
$$

with $\hat{\gamma}_{i}=n_{i} /\left(n_{i}+\hat{\alpha}+\hat{\beta}\right)$ and $\hat{p}=\frac{\widehat{\alpha}}{\widehat{\alpha}+\widehat{\beta}}($ Rao \& Molina, 2015). Next step is calculating MSE of EB estimator with Jackknife and Bootstrap methods.

Jackknife.Jackknife is one of the iteration method which iterates as much as the amount of the data. At first, calculating

$$
\widehat{M}_{1 i}=g_{1 i}\left(\hat{\alpha}, \hat{\beta}, y_{i}\right)-\sum_{\substack{\ell=1 \\ \ell \neq i}}^{m}\left[g_{1 i}\left(\hat{\alpha}_{-\ell}, \hat{\beta}_{-\ell}, y_{i}\right)-g_{1 i}\left(\hat{\alpha}, \hat{\beta}, y_{i}\right)\right]
$$

with $g_{1 i}\left(\hat{\alpha}, \hat{\beta}, y_{i}\right)=\frac{\left(y_{i}+\widehat{\alpha}\right)\left(n_{i}-y_{i}+\widehat{\beta}\right)}{\left(n_{i}+\widehat{\alpha}+\widehat{\beta}+1\right)\left(n_{i}+\widehat{\alpha}+\widehat{\beta}\right)^{2}}$ as naïve variance of EB and $g_{1 i}\left(\hat{\alpha}_{-\ell}, \hat{\beta}_{-\ell}, y_{i}\right)$ is also a naïve variance of EB estimator where $\hat{\alpha}_{-\ell}$ and $\hat{\beta}_{-\ell}$ are $\alpha$ and $\beta$ estimator without involving $\ell^{\text {th }}$ data on its calculation, $\{i=1, \ldots, \ell-1, \ell+1, \ldots, m\}$.Next step is calculating

$$
\widehat{M}_{2 i}=\frac{m-1}{m} \sum_{\ell=1}^{m}\left(\hat{p}_{i,-\ell}^{E B}-\hat{p}_{i}^{E B}\right)^{2} \quad .
$$

with $\hat{p}_{i,-\ell}^{E B}$ is EB estimator where $\hat{\alpha}_{-\ell}$ and $\hat{\beta}_{-\ell}$ are $\alpha$ and $\beta$ estimator without involving $\ell^{\text {th }}$ data on its calculation, $\{i=1, \ldots, \ell-1, \ell+1, \ldots, m\}$ (Slamet, 2011).In accordance with Rao and Molina (2015), MSE estimator with the jackknife method $\left(\operatorname{MSE}\left(\hat{p}_{i}^{E B}\right)\right)$ is obtained by

$$
m s e_{j}\left(\hat{p}_{i}^{E B}\right)=\widehat{M}_{1 i}+\widehat{M}_{2 i}
$$

Bootstrap. In bootstrap method, first thing to do is doing bootstrap resampling for B times in $y_{i j} ; j=1, \ldots, n_{i} ; i=1,2, \ldots, m$ in each area so it yields resampling results in each area with $y_{i j}$ sample that is $y^{*}=\left(y_{1 j}^{*}, y_{2 j}^{*}, \ldots, y_{m j}^{*}\right)$.Then, calculating

$$
\widehat{M}_{1 i, b}=2 g_{1 i}\left(\hat{\alpha}, \hat{\beta}, y_{i}\right)-\frac{1}{B} \sum_{b=1}^{B} g_{1 i}\left(\hat{\alpha}, \hat{\beta}, y_{i}(b)\right) .
$$


with $g_{1 i}\left(\hat{\alpha}, \hat{\beta}, y_{i}(b)\right)$ is naïve variance that uses data $y^{*}=\left(y_{1 j}^{*}, y_{2 j}^{*}, \ldots, y_{m j}^{*}\right)$ which is obtained from the result of bootstrap resampling for B times as the calculation of naive variance estimator. Next step is calculating

$$
\widehat{M}_{2 i, b}=\frac{1}{B} \sum_{b=1}^{B}\left\{\hat{p}_{i}^{E B}(b)-\hat{p}_{i}^{E B}\right\}^{2} .
$$

with $\hat{p}_{i}^{E B}(b)$ is an EB estimator that uses data $y^{*}=\left(y_{1 j}^{*}, y_{2 j}^{*}, \ldots, y_{m j}^{*}\right)$ on a calculation which is obtained from the result of bootstrap resampling for B times(Slamet, 2011).In accordance with Butar \& Lahiri (2003), MSE $\left(\hat{p}_{i}^{E B}\right)$ estimator with the bootstrap method is obtained by

$$
\operatorname{mse}_{b}\left(\hat{p}_{i}^{E B}\right)=\widehat{M}_{1 i, b}+\widehat{M}_{2 i, b} .
$$

RRMSE will be used to compare the result between direct and EB estimator because it can measure the stability of the MSE estimator and gives a more robust result (Chandra, Tzavidis, $\&$ Chambers, 2009). RRMSE can be obtained by

$$
R R M S E=\frac{\sqrt{M S E(\theta)}}{\theta} \times 100 .
$$

where $\theta$ is $\mathrm{EB}$ or direct estimator.

\section{Results and Discussion}

This research uses 3 characteristics data differently that is data with more, moderate, and less proportion of the "success" amount. The result of $\hat{\alpha}$ and $\hat{\beta}$ with the Moment method by Rao or Claire and also with the Newton Raphson method by Rao provides a reasonable and more effective result than the Newton Raphson method by Claire in data with a more and moderate proportion of "success". It provides different result in a less proportion of "success" data that gives the relative same reasonable result of $\hat{\alpha}$ and $\hat{\beta}$ with those 4 methods as seen below.

Table 1.Result of $\hat{\alpha}$ and $\hat{\beta}$ in three types of data.

\begin{tabular}{lcccccccccc}
\hline & \multicolumn{1}{c}{ Methods } \\
\cline { 2 - 12 } $\begin{array}{l}\text { Proportion of } \\
\text { "success" data }\end{array}$ & \multicolumn{4}{c}{ Rao } & \multicolumn{1}{c}{ Moment } & \multicolumn{2}{c}{ Claire } & \multicolumn{4}{c}{ Rewton Raphson } \\
& $\hat{\alpha}$ & & $\hat{\beta}$ & $\hat{\alpha}$ & $\hat{\beta}$ & $\hat{\alpha}$ & $\hat{\beta}$ & $\hat{\alpha}$ & Claire \\
More & 22.95 & 9.03 & 15.67 & 6.14 & 20.55 & 8.04 & $7.43 \mathrm{E}+46$ & $2.87 \mathrm{E}+46$ \\
Moderate & 12.37 & 31.97 & 10.98 & 28.59 & 15.88 & 41.24 & $9.42 \mathrm{E}+36$ & $2.47 \mathrm{E}+37$ \\
Fewer & 3.96 & 106.5 & 1.5 & 39.41 & 4.65 & 121.9 & 1.9867 & 120.97 \\
\hline
\end{tabular}

The result in Table 1 will influence the EB estimator and its MSE value through substitute their value to its formula. All of the estimate $\alpha$ and $\beta$ methods provide reasonable results in each data except Newton Raphson by Claire method in more and moderate data. It can be 
happened because of the characteristics of the data that the Newton Raphson method by Claire is more appropriate in less "success" amounts in binary data.

Table 2.EB estimator results in more and moderate "success" data and method of estimating $\alpha$ and $\beta$

\begin{tabular}{|c|c|c|c|c|c|c|c|}
\hline \multicolumn{4}{|c|}{ More proportion of "success" data } & \multicolumn{4}{|c|}{ Moderate proportion of "success" data } \\
\hline \multicolumn{2}{|c|}{ Rao } & \multicolumn{2}{|c|}{ Claire } & \multicolumn{2}{|c|}{ Rao } & \multicolumn{2}{|c|}{$\begin{array}{l}\text { Claire } \\
\end{array}$} \\
\hline Moment & $\begin{array}{l}\text { Newton } \\
\text { Raphson }\end{array}$ & Moment & $\begin{array}{l}\text { Newton } \\
\text { Raphson }\end{array}$ & Moment & $\begin{array}{l}\text { Newton } \\
\text { Raphson }\end{array}$ & Moment & $\begin{array}{l}\text { Newton } \\
\text { Raphson }\end{array}$ \\
\hline 0.5806 & 0.5788 & 0.5750 & 0.7171 & 0.2737 & 0.2740 & 0.2736 & 0.2789 \\
\hline 0.7329 & 0.7330 & 0.7332 & 0.7171 & 0.2301 & 0.2323 & 0.2293 & 0.2789 \\
\hline 0.6929 & 0.6929 & 0.6927 & 0.7171 & 0.3021 & 0.3011 & 0.3025 & 0.2789 \\
\hline 0.6610 & 0.6607 & 0.6600 & 0.7171 & 0.1904 & 0.1942 & 0.1888 & 0.2789 \\
\hline 0.8231 & 0.8240 & 0.8258 & 0.7171 & 0.2680 & 0.2685 & 0.2678 & 0.2789 \\
\hline 0.8081 & 0.8087 & 0.8097 & 0.7171 & 0.3968 & 0.3919 & 0.3987 & 0.2789 \\
\hline 0.6586 & 0.6582 & 0.6576 & 0.7171 & 0.2834 & 0.2832 & 0.2835 & 0.2789 \\
\hline 0.7918 & 0.7927 & 0.7947 & 0.7171 & 0.2792 & 0.2792 & 0.2792 & 0.2789 \\
\hline
\end{tabular}

Table 3.EB estimator results in less "success" data and method of estimating $\alpha$ and $\beta$

\begin{tabular}{cccc}
\hline \multicolumn{4}{c}{ Less Proportion of "success"data } \\
\hline Rao & Claire & \\
Moment & Newton Raphson & Moment & Newton Raphson \\
0.0218 & 0.0227 & 0.0156 & 0.0225 \\
0.0361 & 0.0361 & 0.0362 & 0.0361 \\
0.0377 & 0.0376 & 0.0383 & 0.0377 \\
0.0191 & 0.0197 & 0.0157 & 0.0196 \\
0.0502 & 0.0492 & 0.0560 & 0.0494 \\
0.0341 & 0.0341 & 0.0337 & 0.0341 \\
0.0458 & 0.0451 & 0.0498 & 0.0453 \\
0.0230 & 0.0241 & 0.0142 & 0.0238 \\
0.0595 & 0.0574 & 0.0763 & 0.0578 \\
0.0261 & 0.0271 & 0.0179 & 0.0269 \\
0.0259 & 0.0265 & 0.0215 & 0.0264 \\
0.0384 & 0.0382 & 0.0396 & 0.0382 \\
0.0367 & 0.0366 & 0.0370 & 0.0366 \\
0.0543 & 0.0534 & 0.0596 & 0.0536 \\
\hline
\end{tabular}

In Table 2 and 3 provide that EB estimator result with Moment or Newton Raphson method by Rao and Moment by Claire for its $\alpha$ and $\beta$ estimators are relatively close to each other in more and moderate proportion of "success" data, but if uses Newton Raphson method by Claire for estimate $\alpha$ and $\beta$ in EB estimator provide same results so it does not give reasonable 
result. This is caused by the value of $\alpha$ and $\beta$ estimators that obtained before is too big so when substituted to the formula of the EB estimator will provide relative same result in each data. But it provides different results in less proportion of "success" data that all of the EB estimators with 4 methods of estimate $\alpha$ and $\beta$ provides relatively reasonable results. Table 4 below shows that the direct estimator in each data is relatively close to the EB estimator in Table 2 and 3.

Table 4. Table title. Table captions should always be positioned above the tables.

\begin{tabular}{|c|c|c|c|c|c|c|c|c|}
\hline $\begin{array}{l}\text { The } \\
\text { Proportion } \\
\text { of } \\
\text { "success" } \\
\text { data }\end{array}$ & \multicolumn{8}{|c|}{ Direct Estimator } \\
\hline More & 0.5614 & 0.7338 & 0.6920 & 0.6578 & 0.8320 & 0.8134 & 0.6554 & 0.8017 \\
\hline Moderate & 0.273 & 0.221 & 0.307 & 0.174 & 0.266 & 0.417 & 0.284 & 0.279 \\
\hline Fewer & 0.0085 & 0.0364 & 0.0389 & 0.0130 & 0.0625 & 0.0333 & 0.0543 & 0 \\
\hline rewe & 0.1053 & 0 & 0.0167 & 0.0412 & 0.0373 & 0.0644 & & \\
\hline
\end{tabular}

To see the performance of each estimator, we will see in its RRMSE value as in Table 5. All of the RRMSE value of EB estimators are smaller than RRMSE of direct estimator so EB method is more effective than the direct method. But there are several not reasonable result in RRMSE of EB estimator. For instance, a Bootstrap method with Newton Raphson by Rao provides zero value of RRMSE estimator in each data while bootstrap and jackknife method with Newton raphson by Claire provide zero value in a more and moderate proportion of "success" data. But it does not happen in a less proportion of "success" data. It can be caused by $\alpha$ and $\beta$ estimators that obtained before with Newton Raphson and has an effect on the characteristics of the data. Besides that, this research uses $\mathrm{R}$ programming for calculating the estimate that has a limited memory capacity.

Table 5.RRMSE value of each data with certain method

\begin{tabular}{|c|c|c|c|c|c|c|c|c|c|}
\hline \multirow{3}{*}{ Data } & \multicolumn{4}{|c|}{ Rao } & \multicolumn{4}{|c|}{ Claire } & \multirow{3}{*}{$\begin{array}{l}\text { direct } \\
\text { estimat } \\
\text { or }\end{array}$} \\
\hline & \multicolumn{2}{|c|}{ Moment } & \multicolumn{2}{|c|}{ Newton Raphson } & \multicolumn{2}{|c|}{ Moment } & \multicolumn{2}{|c|}{ Newton Raphson } & \\
\hline & $\begin{array}{c}\text { Jackkni } \\
\text { fe }\end{array}$ & $\begin{array}{c}\text { Bootstr } \\
\text { ap }\end{array}$ & $\begin{array}{c}\text { Jackkni } \\
\text { fe }\end{array}$ & $\begin{array}{c}\text { Bootstr } \\
\text { ap }\end{array}$ & $\begin{array}{c}\text { Jackkni } \\
\text { fe }\end{array}$ & $\begin{array}{c}\text { Bootstr } \\
\text { ap }\end{array}$ & $\begin{array}{c}\text { Jackkni } \\
\text { fe }\end{array}$ & $\begin{array}{c}\text { Bootstr } \\
\text { ap }\end{array}$ & \\
\hline \multirow{8}{*}{$\begin{array}{l}\text { More } \\
\text { Proporti } \\
\text { on of } \\
\text { "success } \\
\text { " data }\end{array}$} & 5.456 & 5.276 & 5.599 & 0 & 5.611 & 5.416 & 0 & 0 & 5.854 \\
\hline & 2.462 & 2.454 & 2.485 & 0 & 2.487 & 2.470 & 0 & 0 & 2.521 \\
\hline & 2.240 & 2.234 & 2.256 & 0 & 2.258 & 2.246 & 0 & 0 & 2.283 \\
\hline & 2.946 & 2.930 & 2.979 & 0 & 2.983 & 2.956 & 0 & 0 & 3.037 \\
\hline & 2.329 & 2.284 & 2.345 & 0 & 2.328 & 2.285 & 0 & 0 & 2.302 \\
\hline & 2.038 & 2.017 & 2.050 & 0 & 2.043 & 2.020 & 0 & 0 & 2.039 \\
\hline & 2.895 & 2.879 & 2.926 & 0 & 2.930 & 2.904 & 0 & 0 & 2.980 \\
\hline & 3.144 & 3.095 & 3.190 & 0 & 3.178 & 3.114 & 0 & 0 & 3.198 \\
\hline Moderat & 10.815 & 9.773 & 10.789 & 0 & 10.417 & 9.795 & 0 & 0 & 10.744 \\
\hline $\mathrm{e}$ & 13.389 & 11.045 & 13.460 & 0 & 12.212 & 11.067 & 0 & 0 & 12.361 \\
\hline proporti & 10.453 & 9.227 & 10.495 & 0 & 9.927 & 9.229 & 0 & 0 & 10.024 \\
\hline on of & 18.362 & 12.553 & 18.692 & 0 & 15.156 & 12.517 & 0 & 0 & 14.196 \\
\hline "success & 11.215 & 10.083 & 11.180 & 0 & 10.779 & 10.110 & 0 & 0 & 11.156 \\
\hline
\end{tabular}




\begin{tabular}{|c|c|c|c|c|c|c|c|c|c|}
\hline \multirow{3}{*}{ Data } & \multicolumn{4}{|c|}{ Rao } & \multicolumn{4}{|c|}{ Claire } & \multirow{3}{*}{$\begin{array}{l}\text { direct } \\
\text { estimat } \\
\text { or }\end{array}$} \\
\hline & \multicolumn{2}{|c|}{ Moment } & \multicolumn{2}{|c|}{ Newton Raphson } & \multicolumn{2}{|c|}{ Moment } & \multicolumn{2}{|c|}{ Newton Raphson } & \\
\hline & $\begin{array}{c}\text { Jackkni } \\
\text { fe }\end{array}$ & $\begin{array}{l}\text { Bootstr } \\
\text { ap }\end{array}$ & $\begin{array}{c}\text { Jackkni } \\
\text { fe }\end{array}$ & $\begin{array}{c}\text { Bootstr } \\
\text { ap }\end{array}$ & $\begin{array}{c}\text { Jackkni } \\
\text { fe }\end{array}$ & $\begin{array}{c}\text { Bootstr } \\
\text { ap }\end{array}$ & $\begin{array}{c}\text { Jackkni } \\
\text { fe }\end{array}$ & $\begin{array}{c}\text { Bootstr } \\
\text { ap }\end{array}$ & \\
\hline \multirow[t]{4}{*}{ " data } & 11.010 & 7.278 & 11.598 & 0 & 8.872 & 7.168 & 0 & 0 & 7.414 \\
\hline & 11.012 & 9.901 & 10.985 & 0 & 10.594 & 9.920 & 0 & 0 & 10.921 \\
\hline & 10.858 & 9.798 & 10.832 & 0 & 10.458 & 9.819 & 0 & 0 & 10.782 \\
\hline & 51.241 & 48.596 & 55.401 & 0 & 66.142 & 65.285 & 16.199 & 32.665 & 99.572 \\
\hline \multirow{12}{*}{$\begin{array}{l}\text { Less } \\
\text { proporti } \\
\text { on of } \\
\text { "success } \\
\text { " data }\end{array}$} & 36.092 & 30.850 & 38.415 & 0 & 42.995 & 40.882 & 0 & 27.965 & 49.082 \\
\hline & 30.802 & 27.312 & 32.796 & 0 & 34.375 & 33.103 & 0 & 25.397 & 37.054 \\
\hline & 39.457 & 37.915 & 43.615 & 0 & 43.323 & 42.995 & 33.907 & 29.193 & 49.673 \\
\hline & 30.575 & 25.621 & 34.027 & 0 & 32.713 & 30.694 & 0 & 24.490 & 34.233 \\
\hline & 28.256 & 26.026 & 29.774 & 0 & 30.826 & 30.073 & 0 & 24.063 & 32.773 \\
\hline & 31.347 & 26.436 & 34.296 & 0 & 34.522 & 32.567 & 0 & 25.230 & 36.757 \\
\hline & 58.058 & 55.486 & 61.698 & 0 & 88.936 & 88.303 & 46.314 & 34.061 & NA \\
\hline & 35.317 & 28.423 & 40.657 & 0 & 37.776 & 33.566 & 0 & 26.500 & 38.616 \\
\hline & 55.375 & 50.700 & 58.274 & 0 & 87.860 & 85.773 & 0 & 33.456 & NA \\
\hline & 44.051 & 40.440 & 47.072 & 0 & 54.706 & 53.273 & 0 & 30.860 & 70.119 \\
\hline & 36.031 & 30.090 & 38.534 & 0 & 43.014 & 40.558 & 0 & 27.844 & 48.958 \\
\hline & 32.304 & 28.485 & 34.358 & 0 & 36.655 & 35.230 & 0 & 26.223 & 40.057 \\
\hline
\end{tabular}

Moment method by Rao or Claire and Newton Raphson by Rao for estimate $\alpha$ and $\beta$ are more effective than Newton Raphson by Claire because in any type of data characteristics provide reasonable results than newton raphson by Claire. But in a fewer proportion of "success" data provide a different result that can be caused by the small number of "success" categories in each data. If seen further, it can be happened caused by the number of data that more the number of the data then make an estimate of $\alpha$ and $\beta$ with newton raphson by Claire more effectively. So in this research also do calculating the result in poverty proportion data in Aceh regency and a part of the North Sumatra Regency in 2017. The number of the data is 50 and provide $\alpha$ and $\beta$ estimators from newton raphson by Claire is also not reasonable. Hence, the number of the data does not quiet influence to newton raphson method by Claire. So that, the moment method by Rao or Claire and newton Raphson by Rao are more effective than newton Raphson by Claire in the EB estimator. Besides that, this research implements simulation with generated data from normal distribution with parameter is the average and standard deviation of each the data to see performance of those $\alpha$ and $\beta$ estimator methods. Simulation is done 30 times in each type of data. The result of simulation shows that moment and newton raphson method by Rao give a reasonable result in less, moderate, and more proportion of "success" data. Moment method by Claire also provide reasonable result in less, moderate, and more proportion of "success" data. Same as journal data result, Newton Raphson method by Claire gives relatively unreasonable result in moderate and more proportion of "success" data. Unique event occur again on less proportion of "success" data that give an unreasonable result in almost all of the simulation. It is quiet different with journal data. However in that simulation, there are four generated data give a reasonable result of $\alpha$ and $\beta$ estimators in less proportion of "success" data.

Table 6.A few simulation result in more proportion of "success" data.

\begin{tabular}{lcccccc}
\hline & $\hat{\alpha}$ & $\hat{\beta}$ & $\hat{\alpha}$ & $\hat{\beta}$ & $\hat{\alpha}$ & $\hat{\beta}$ \\
\hline $\begin{array}{l}\text { Moment } \\
\text { by Rao }\end{array}$ & 22.10 & 9.074478 & 14.89273 & 6.890818 & 23.18375 & 9.446278
\end{tabular}




\begin{tabular}{lcccccc}
$\begin{array}{l}\text { Moment } \\
\text { by } \\
\begin{array}{l}\text { Claire } \\
\text { Newton }\end{array}\end{array}$ & 17.81 & 6.755412 & 15.27466 & 6.605055 & 20.04384 & 7.003688 \\
$\begin{array}{l}\text { Raphson } \\
\text { by Rao }\end{array}$ & 21.16 & 8.049733 & 19.84027 & 8.656791 & 21.30833 & 7.507306 \\
$\begin{array}{l}\text { Newton } \\
\text { Raphson } \\
\text { by }\end{array}$ & $7.58 \mathrm{E}+33$ & $2.84 \mathrm{E}+33$ & $1.05 \mathrm{E}+19$ & $4.51 \mathrm{E}+18$ & $1.03 \mathrm{E}+20$ & $3.57 \mathrm{E}+19$ \\
Claire & & & & & & \\
\hline
\end{tabular}

Table 7.A few simulation result in moderate proportion of "success" data.

\begin{tabular}{lcccccc}
\hline & $\hat{\alpha}$ & $\hat{\beta}$ & $\hat{\alpha}$ & $\hat{\beta}$ & $\hat{\alpha}$ & $\hat{\beta}$ \\
\hline $\begin{array}{l}\text { Moment } \\
\text { by Rao }\end{array}$ & 11.17013 & 31.27962 & 22.34463 & 47.43326 & 1.497158 & 7.130114 \\
$\begin{array}{l}\text { Moment } \\
\text { by }\end{array}$ & 14.67847 & 36.29469 & 15.78873 & 33.40795 & 6.594077 & 18.93325 \\
$\begin{array}{l}\text { Claire } \\
\text { Newton }\end{array}$ & & & & & & \\
$\begin{array}{l}\text { Raphson } \\
\text { by Rao }\end{array}$ & 17.18166 & 43.36674 & 26.99131 & 57.15908 & 5.156115 & 15.25522 \\
$\begin{array}{l}\text { Newton } \\
\text { Raphson } \\
\text { by }\end{array}$ & $1.98 \mathrm{E}+24$ & $4.93 \mathrm{E}+24$ & $2.51 \mathrm{E}+24$ & $5.34 \mathrm{E}+24$ & $5.05 \mathrm{E}+74$ & $1.47 \mathrm{E}+75$ \\
Claire & & & & & & \\
\hline
\end{tabular}

Table 8.A few simulation result in less proportion of "success" data.

\begin{tabular}{lcccccc}
\hline & $\hat{\alpha}$ & $\hat{\beta}$ & $\hat{\alpha}$ & $\hat{\beta}$ & $\hat{\alpha}$ & $\hat{\beta}$ \\
\hline $\begin{array}{l}\text { Moment } \\
\text { by Rao } \\
\text { Moment }\end{array}$ & 0.011394 & 3.226975 & 1.08064 & 44.10915 & 2.149088 & 105.8847 \\
by & 1.281743 & 28.3167 & 1.77663 & 42.55419 & 1.358526 & 44.66597 \\
$\begin{array}{l}\text { Claire } \\
\text { Newton }\end{array}$ & & & & & & \\
$\begin{array}{l}\text { Raphson } \\
\text { by Rao }\end{array}$ & 0.011394 & 3.226975 & 2.030684 & 52.79175 & 4.271752 & 171.4406 \\
$\begin{array}{l}\text { Newton } \\
\text { Raphson } \\
\text { by }\end{array}$ & 1.116707 & 57.12286 & $1.71 \mathrm{E}+98$ & $4.35 \mathrm{E}+99$ & 3.897466 & 295.0626 \\
Claire & & & & & & \\
\hline
\end{tabular}




\section{Conclusion}

Moment method by Claire, moment and Newton Raphson method by Rao are more effective in estimating $\alpha$ and $\beta$ than Newton Raphson method by Claire in Empirical Bayes of Small Area Estimation although Newton Raphson by Claire is reasonable in a few of less proportion of "success" data. It can be happened because the influence of characteristic of the data that caused the result of $\alpha$ and $\beta$ estimators. Besides that, the results of area estimator from Empirical Bayes are more effective than direct estimator because its RRMSE value are smaller than RRMSE value of direct estimator. 


\section{References}

[1]Butar, F. B., \& Lahiri, P. (2003). On measures of uncertainty of empirical bayes small area estimators. Journal of Statistical Planning and Inference, 63-76.

[2]Chandra, H., Tzavidis, N., \& Chambers, R. (2009). On Bias-Robust Mean Squared Error Estimation for Pseudo-Linear Small Area Estimation. Centre for Statistical and Survey Methodology, University of Wollongong, 11-09.

[3]Kismiantini. (dátum neznámy). Penerapan Metode Bayes Empirik pada Pendugaan Area Kecil untuk Kasus Biner (Studi tentang Proporsi Status Kepemilikan Kartu Sehat di Kota Yogyakarta). Jurusan Pendidikan Matematika FMIPA Universitas Negeri Yogyakarta.

[4]Kleinman, J. C. (1973). Proportions with Extraneous Variance: Single and Independent Samples. Journal of the American Statistical Association, 46-54. doi:10.1080/01621459.1973.10481332

[5]Molina, I., \& Marhuenda, Y. (2015). sae: An R Package for Small Area Estimation. Contributed Research Articles, 7(1), 81-98.

[6]Ogundeji, R., Adewara, A., \& Nurudeen, T. (2012). Bayesian Sequential Estimation of Proportion of Orthopaedic Surgery Among Different Age Groups: A Case Study of National Orthopaedic Hospital, Igbobi - Nigeria. International Journal of Statistics and Applications, 2(6), 108-113. doi:10.5923/j.statistics.20120206.03

[7]Ogundeji, R., Adewara, A., \& Nurudeen, T. (2013). Bayesian Estimation of AboveAverage Performance in Tertiary Institutions: A Case Study of University of Lagos, Akoka, Nigeria. IOSR Journal of Mathematics (IOSR-JM), 6(5), 01-07.

[8]Oka, B. T., Sumarjaya, I. W., \& Ariwijayanthi, P. E. (2013). Penerapan Metode Pendugaan Area Kecil pada Penentuan Proporsi Rumah Tangga Miskin di Kabupaten Klungkung. E-Jurnal Matematika, 2(3), 35-39.

[9]Owen, C. E. (2008). Parameter Estimation for the Beta Distribution. Provo: Brigham Young University.

[10]R.O, O., \& U.A., M. (2011). A Bayesian Model for Estimation of Population Proportions. Section on Bayesian Statistical Science-JSM 2011, 632-641.

[11]Rao, J. (2003). Small Area Estimation. Canada: John Wiley \& Sons Inc.

[12]Rao, J., \& Molina, I. (2015). Small Area Estimation Second Edition. Canada: John Wiley $\&$ Sons Inc.

[13]Slamet, A. (2011). Pendugaan Statistik Area Kecil menggunakan Model Beta-Binomial. Bogor: Institut Pertanian Bogor.

[14]Sosial, S. D. (2018). Data dan Informasi Kemiskinan Kabupaten/Kota Tahun 2017. Jakarta: Badan Pusat Statistik.

[15]Wilcox, R. R. (1979). Estimating the Parameters of the Beta-Binomial Distribution. Educational and Psycological Measurement(39), 527-535.

[16]Zain, I., \& Sidabutar, L. H. (2015). Small Area Estimation dengan Pendekatan Empirical Bayes Berbasis Model Beta-Binomial untuk Estimasi Angka Pengangguran di Kabupaten Sumba Timur. SENATEK 2015, 639-644. 
